\title{
Oxidative Stress as a Risk Factor for Hearing Changes in HIV-positive Normal Listeners
}

\author{
Carla G. Matas (iD) * Fernanda Yasmin OMM Padilha iD, Rosanna MG Angrisani iD, Alessandra G. Samelli iD \\ Curso de Fonoaudiologia, Faculdade de Medicina (FMUSP), Universidade de Sao Paulo, Sao Paulo, SP, BR.
}

Matas CG, Padilha FYOMM, Angrisani RMG, Samelli AG. Oxidative Stress as a Risk Factor for Hearing Changes in HIV-positive Normal Listeners. Clinics. 2020;75:e1845

*Corresponding author. E-mail: cgmatas@usp.br

\begin{abstract}
OBJECTIVES: Human immunodeficiency virus-positive (HIV + ) individuals can experience a decrease in antioxidants. Such deficiency can make inner ear cells and synapses more vulnerable to oxidative stress, resulting in auditory alterations, even in the presence of normal thresholds. This study aims to compare the audiological findings of HIV + patients (with and without exposure to anti-retroviral treatment) to those of healthy individuals.

METHODS: This was a cross-sectional observational study, comprising 42 normal-hearing adults divided into the Control Group (CG), without HIV; Group I (GI), HIV +, without exposure to the highly active anti-retroviral therapy (HAART); Group II (GII), HIV+, with exposure to HAART. All participants underwent conventional audiometry $(0.25-8 \mathrm{kHz})$, high-frequency audiometry $(9-20 \mathrm{kHz})$, transient evoked otoacoustic emissions (TEOAEs), efferent auditory pathway's inhibitory effect assessment, brainstem auditory evoked potentials (BAEPs), and cognitive potential (P300).

RESULTS: In the comparison of the hearing thresholds between the groups, there was a statistically significant difference for most of the frequencies assessed (GII presented hearing thresholds significantly poor when compared with other groups). The presence of TEOAE and the inhibitory effect was also verified in a significantly higher number of individuals in the CG than in the other groups. As for the BAEP, there was a statistically significant difference for the interpeak intervals I-V (GII showed higher values when compared with CG). For P300, there were no statistically significant differences.

CONCLUSION: Normal-hearing HIV + individuals (with and without exposure to HAART) presented with poor performance in the audiological procedures, suggesting the presence of auditory alterations even in the presence of normal-hearing thresholds.
\end{abstract}

KEYWORDS: HIV; Hearing; Hearing Disorders; Oxidative Stress; Hearing Tests.

\section{INTRODUCTION}

Acquired immunodeficiency syndrome (AIDS) is caused by the human immunodeficiency virus (HIV), a specific type of retrovirus that affects the immune system, possibly leading to various opportunistic infections and potentially affecting the central nervous system (1).

Many HIV-infected individuals present with a preserved level of immune cells, remaining asymptomatic for long periods, not clinically manifesting the disease. According to the Brazilian Ministry of Health (2), HIV-seropositive individuals are considered to have AIDS when their CD4 + T lymphocyte count is lower than 350 cells $/ \mathrm{mm}^{3}$.

Copyright $\odot 2020$ CLINICS - This is an Open Access article distributed under the terms of the Creative Commons License (http://creativecommons.org/licenses/by/ 4.0/) which permits unrestricted use, distribution, and reproduction in any medium or format, provided the original work is properly cited.

No potential conflict of interest was reported.

Received for publication on March 26, 2020. Accepted for publication on September 24, 2020

DOI: $10.6061 /$ clinics/2020/e1845
Currently, the most commonly used therapy in infected individuals is the highly active anti-retroviral therapy (HAART), which involves the use of at least three drugs and monitoring the viral plasma concentration (3).

Hearing loss in HIV-positive individuals can be caused by various factors, including direct effects from HIV, increased susceptibility to opportunistic infections in the middle ear and central nervous system, and treatment with potentially ototoxic medications $(4,5)$.

Reactive oxygen species (ROS) are oxygen mediators with a high reactive capacity for many biological molecules. ROS are produced during various cellular processes and in many organelles (6).

In certain pathological conditions or when several medications are being taken, the exaggerated production of ROS takes place, leading to what is known as oxidative stress. Oxidative stress is caused by the imbalance between ROS production and its removal through strategies and antioxidants available in the organism, including enzymes, proteins, molecules, and vitamins (7).

In individuals with HIV, the depletion of antioxidants essential for the maintenance of the electrolytic balance of the immune system cells can occur, causing a decrease in 
immune response, and consequently, an increase in HIV replication, possibly aggravating the patient's condition $(8,9)$.

A previous study has shown that individuals with HIV have increased levels of biomarkers of oxidative damage to deoxyribonucleic acid (DNA) in the CD4 + T cells, as well as decreased DNA glycosylase activity for the repair of oxidative-based lesions in those cells (10).

Studies have shown that oxidative stress contributes to the death of hair cells, which can lead to auditory alterations $(11,12)$. Recently, the oxidative stress resulting from noise exposure (13-15) and ototoxic medications $(4,16)$ are being related to auditory alterations, even in the presence of hearing thresholds within normality (16-18). This condition is called hidden hearing loss, which can be characterized by the presence of auditory complaints (tinnitus, hyperacusis, reduced speech-in-noise intelligibility) in individuals with normal-hearing thresholds (19-21). Thus, these possible auditory alterations would be verified through other tests, in addition to conventional audiometry.

Hence, it is important that different conditions (for instance, the presence of HIV and/or the use of anti-retroviral medications) that generate oxidative stress be evaluated, for understanding the influence of these factors on the auditory system to advance.

This study aims to compare the audiological findings of $\mathrm{HIV}+$ patients (with and without exposure to anti-retroviral treatment) to those of healthy individuals, all of whom had hearing thresholds within normality.

\section{MATERIAL AND METHODS}

This was a cross-sectional observational study, approved by the Ethics Committee for the Analysis of Research Projects (CAPPesq - Medical School Clinics Hospital of the University of São Paulo - FMUSP) under the number 1026/04. All the participants signed the informed consent form in compliance with the Brazilian National Health Council Resolution 466/12.

The sample comprised 42 individuals with normal-hearing (hearing threshold $<25 \mathrm{~dB} \mathrm{HL}$ in the frequencies of 0.25 to $8 \mathrm{kHz}$ ) (22), with an age range of 25-52 years. The individuals were divided into three groups with their respective inclusion criteria:

- Group I (GI), comprising 13 HIV-positive individuals (verified through serology) without exposure to antiretroviral treatment;

- Group II (GII), comprising 14 HIV-positive individuals (verified through serology) exposed to anti-retroviral treatment (combined therapy or HAART, which consists of at least three of the following medications: lamivudine, zidovudine, efavirenz, didanosine, nevirapine, lopinavir, tenofovir, stavudine, indinavir, abacavir, amprenavir, ritonavir, and atazanavir);

- Control Group (CG), comprising 15 individuals without HIV (evaluation report and seronegative); audiological, language, or auditory processing complaints; and any history of psychiatric or neurological diseases.

The following exclusion criteria were considered for the three above-mentioned groups: pure-tone audiometry with altered hearing thresholds, presence of active opportunistic infections, presence of clinical and/or cognitive impairment preventing or hindering audiological and/or electrophysiological examinations to be performed, and history of otologic surgery and/or otologic diseases unrelated to HIV.

GI and GII were referred by the House of AIDS - Zerbini Foundation and by the municipal system health services specialized in sexually transmitted diseases (STD/AIDS) of the São Paulo Municipal Department of Health. The CG comprised a convenience sample.

\section{Procedures}

The medical reports of the individuals from GI and GII were analyzed; their otologic history was verified through anamnesis.

The audiological assessment included the visual inspection of the external acoustic meatus; acoustic immittance measures (tympanometry and acoustic reflexes) to verify the condition of the middle ear; conventional air-conduction pure-tone threshold audiometry at the frequencies of 0.25 to $8 \mathrm{kHz}$; and air-conduction high-frequency audiometry at 9 to $20 \mathrm{kHz}$ (Grason-Stadler GSI 61, TDH-50 earphones) in an acoustically treated room, with standard audiometric techniques.

Subsequently, for the transient evoked otoacoustic emissions (TEOAEs) to be picked up with and without contralateral noise, the ILO 92 (Otodynamics) system was used. The stimulus was a nonlinear click with an intensity ranging from 78-84 dB SPL peak. For the TEOAE, the responses were considered present when the signal-to-noise ratio was greater than $3 \mathrm{~dB}$ SPL in all frequency bands (23). In the cases where the TEOAEs were present, the efferent auditory pathway's inhibitory effect was calculated by subtracting the TEOAE amplitudes in the presence of noise (white noise to the contralateral ear at $60 \mathrm{~dB}$ SPL) from the TEOAE amplitudes in the absence of noise. Differences resulting in positive values were considered the presence of an efferent auditory pathway's inhibitory effect (24).

To perform the electrophysiological assessment (brainstem auditory evoked potential [BAEP] and cognitive potential [P300]), the Express Traveler Portable System, from BioLogic, was used, along with THD-39 earphones.

For the BAEP, the click stimulus with rarefied polarity was used, presented monaurally at $80 \mathrm{~dB} \mathrm{HL}$, at a presenting speed of $19.3 / \mathrm{s}$, lasting 0.1 milliseconds, totaling 2,048 stimuli. The absolute latency values of waves I, III, and V, as well as interpeak intervals I-III, III-V, I-V, were analyzed using the normality standard proposed by the Evoked Potential User Manual of Bio-Logic.

To pick up the P300, the tone-burst stimulus was used, presented monaurally at $75 \mathrm{~dB} \mathrm{HL}$, at a presenting speed of 1.1 stimulus per second, totaling 300 stimuli. The frequent stimulus $(80 \%-240$ stimuli) was presented at $1,000 \mathrm{~Hz}$, and the rare stimulus (20\% - 60 stimuli) at $1,500 \mathrm{~Hz}$. The individuals were instructed to remain alert and pay attention to the rare stimuli, which appeared randomly among a series of frequent stimuli (oddball paradigm), mentally counting whenever they appeared (thus performing the cognitive activity). In the trace resulting from the subtraction of the rare stimulus from the frequent stimulus, the latency of the P300 component was analyzed. As normality criteria, the values proposed by McPherson (25) were considered for P300 latency waves.

\section{Statistical analysis}

Descriptive analyses and hypotheses tests were conducted. The one-factor Analysis of variance (ANOVA), Tukey's, and 
chi-square tests were used. Initially, the left and right ears of each group were compared for each procedure. As no significant differences were found, the right and left ears were grouped together and then compared between the groups. A $p$-value $<0.05$ was considered significant.

\section{RESULTS}

Regarding the hearing thresholds, statistically significant differences were verified between the groups for all frequencies assessed in the conventional and high-frequency audiometry, except for $9 \mathrm{kHz}$. In general, it was noted that individuals in the CG presented better hearing thresholds compared with those in GI and GII, and in turn, the GI's hearing thresholds were better than those of GII (Tables 1 and 2).

Table 3 shows the distribution of individuals by the TEOAE results (presence or absence), as well as of the efferent auditory pathway's inhibitory effect. It was verified that the CG presented $100 \%$ present responses for TEOAE, while the other two groups presented approximately $50 \%$. As for the inhibitory effect, with a statistically significant difference, the CG showed more present responses when compared with the other two groups.
Concerning the P300 and BAEP latencies, the three groups presented similar values (Table 4 ). The only statistically significant difference was observed for interpeak I-V, in which GII's values were higher when compared with the CG.

Table 5 shows the distribution of normal or altered results of individuals by each electrophysiological procedure. For BAEP, when compared with GI and GII, there was a significantly higher number of normal results in CG. GII presented a higher alteration percentage when compared with GI and CG. For P300, there were no statistically significant differences between the groups.

\section{DISCUSSION}

Oxidative stress occurs when ROSs reach high levels, which cannot be neutralized by the defense mechanisms, thus damaging and altering the functions of biological molecules, potentially harming the cells. These alterations can be observed in the presence of pathological conditions, as in the case of AIDS, and when various medications are being taken, as, for instance, anti-retrovirals $(6,26)$. In the auditory system, oxidative stress can make cells more vulnerable, contributing to the death of cells and alterations in the auditory pathway $(11,12)$.

Table 1 - Mean and standard deviation (in $\mathrm{dB} \mathrm{HL}$ ) of the auditory thresholds from 0.25 to $8 \mathrm{kHz}$ of both the ears, by group

\begin{tabular}{|c|c|c|c|c|c|c|c|c|}
\hline \multirow[b]{2}{*}{ Groups } & \multirow{2}{*}{$\frac{250 \mathrm{~Hz}}{\text { Mean (SD) }}$} & \multirow{2}{*}{$\frac{500 \mathrm{~Hz}}{\text { Mean (SD) }}$} & \multirow{2}{*}{$\frac{1,000 \mathrm{~Hz}}{\text { Mean (SD) }}$} & \multirow{2}{*}{$\frac{2,000 \mathrm{~Hz}}{\text { Mean (SD) }}$} & \multirow{2}{*}{$\frac{3,000 \mathrm{~Hz}}{\text { Mean (SD) }}$} & \multirow{2}{*}{$\frac{4,000 \mathrm{~Hz}}{\text { Mean (SD) }}$} & \multirow{2}{*}{$\frac{6,000 \mathrm{~Hz}}{\text { Mean (SD) }}$} & \multirow{2}{*}{$\frac{8,000 \mathrm{~Hz}}{\text { Mean (SD) }}$} \\
\hline & & & & & & & & \\
\hline GI $(n=26)$ & $9(7.3)$ & $8(6.4)$ & $6.5(5.2)$ & $3.8(5.8)$ & $6.7(7.2)$ & $9.4(6)$ & $12.8(6.8)$ & $11.5(8.8)$ \\
\hline GII $(n=28)$ & $12.5(6.7)$ & $10.5(6.2)$ & $8.5(5.2)$ & $8(6.7)$ & $10(6.6)$ & $10.8(8.7)$ & $13(9.1)$ & $13(6.8)$ \\
\hline CG $(n=30)$ & $6.7(4)$ & $4.8(3.8)$ & $5.1(4.2)$ & $4(4.4)$ & $4(4.6)$ & $6(5.7)$ & $6(6.7)$ & $6.5(6)$ \\
\hline$p$-value & $0.002 *$ & $0.001 *$ & $0.035^{*}$ & $0.011 *$ & $0.002^{*}$ & 0.027 * & $<0.001 *$ & $0.002 *$ \\
\hline \multirow[t]{3}{*}{ Tukey's test } & $\mathrm{GI}=\mathrm{GII}$ & $\mathrm{Gl}=\mathrm{GII}$ & $\mathrm{Gl}=\mathrm{GII}$ & $\mathrm{GI} \neq \mathrm{GII}$ & $\mathrm{Gl}=\mathrm{GII}$ & $\mathrm{GI}=\mathrm{GII}$ & $\mathrm{Gl}=\mathrm{GII}$ & $\mathrm{GI}=\mathrm{GII}$ \\
\hline & $\mathrm{Gl}=\mathrm{CG}$ & $\mathrm{Gl}=\mathrm{CG}$ & $\mathrm{Gl}=\mathrm{CG}$ & $\mathrm{Gl}=\mathrm{CG}$ & $\mathrm{Gl}=\mathrm{CG}$ & $\mathrm{Gl}=\mathrm{CG}$ & $\mathrm{GI} \neq \mathrm{CG}$ & $\mathrm{GI} \neq \mathrm{CG}$ \\
\hline & $\mathrm{GII} \neq \mathrm{CG}$ & $\mathrm{GII} \neq \mathrm{CG}$ & $\mathrm{GII} \neq \mathrm{CG}$ & $\mathrm{GII} \neq \mathrm{CG}$ & $\mathrm{GII} \neq \mathrm{CG}$ & $\mathrm{GII} \neq \mathrm{CG}$ & $\mathrm{GII} \neq \mathrm{CG}$ & $\mathrm{GII} \neq \mathrm{CG}$ \\
\hline
\end{tabular}

ANOVA test. * $p$-value<0.05; SD: Standard deviation; GI: Group I; GII: Group II; CG: Control Group.

Table 2 - Mean and standard deviation (in $\mathrm{dB} \mathrm{HL}$ ) of the auditory thresholds from 9 to $20 \mathrm{kHz}$ of both the ears, by group.

\begin{tabular}{|c|c|c|c|c|c|c|c|c|}
\hline & $9 \mathrm{kHz}$ & $10 \mathrm{kHz}$ & $11.2 \mathrm{kHz}$ & $12.5 \mathrm{kHz}$ & $14 \mathrm{kHz}$ & $16 \mathrm{kHz}$ & $18 \mathrm{kHz}$ & $20 \mathrm{kHz}$ \\
\hline Groups & Mean (SD) & Mean (SD) & Mean (SD) & Mean (SD) & Mean (SD) & Mean (SD) & Mean (SD) & Mean (SD) \\
\hline GI $(n=26)$ & $13.9(10.2)$ & $11.6(11.4)$ & $16.6(15.1)$ & $24.3(24.9)$ & $29.7(26.2)$ & $28.7(22.7)$ & $18.7(12.1)$ & $6.8(7)$ \\
\hline GII $(n=28)$ & $16.5(9.9)$ & $17(9.3)$ & $24.7(11.3)$ & $28.1(18.2)$ & $42.7(19.4)$ & $48.1(9.3)$ & $31.1(5.5)$ & $10.9(6.2)$ \\
\hline CG $(n=30)$ & $11(8.5)$ & $8.8(9.1)$ & $10.5(11.6)$ & $14.3(14.7)$ & 18 (17.1) & $21(15.8)$ & $14(10)$ & $2.6(3.8)$ \\
\hline$p$-value & 0.115 & $0.017^{*}$ & $0.001 *$ & $0.033^{*}$ & $<0.001 *$ & $<0.001 *$ & $<0.001 *$ & $<0.001 *$ \\
\hline \multirow[t]{3}{*}{ Tukey's test } & - & $\mathrm{GI}=\mathrm{GII}$ & $\mathrm{GI}=\mathrm{GII}$ & $\mathrm{GI}=\mathrm{GII}$ & $\mathrm{GI}=\mathrm{GII}$ & $\mathrm{GI} \neq \mathrm{GII}$ & $\mathrm{GI} \neq \mathrm{GII}$ & $\mathrm{GI}=\mathrm{GII}$ \\
\hline & & $\mathrm{Gl}=\mathrm{CG}$ & $\mathrm{GI}=\mathrm{CG}$ & $\mathrm{Gl}=\mathrm{CG}$ & $\mathrm{Gl}=\mathrm{CG}$ & $\mathrm{Gl}=\mathrm{CG}$ & $\mathrm{Gl}=\mathrm{CG}$ & $\mathrm{GI} \neq \mathrm{CG}$ \\
\hline & & $\mathrm{GII} \neq \mathrm{CG}$ & $\mathrm{GII} \neq \mathrm{CG}$ & $\mathrm{GII} \neq \mathrm{CG}$ & $\mathrm{GII} \neq \mathrm{CG}$ & $\mathrm{GII} \neq \mathrm{CG}$ & $\mathrm{GII} \neq \mathrm{CG}$ & $\mathrm{GII} \neq \mathrm{CG}$ \\
\hline
\end{tabular}

ANOVA test. * $p$-value $<0.05$; SD: Standard deviation; GI: Group I; GII: Group II; CG: Control Group.

Table 3 - Distribution of the TEOAE results (presence or absence) and efferent auditory pathway's inhibitory effect results, by individual (number and percentage).

\begin{tabular}{|c|c|c|c|c|}
\hline \multirow[b]{2}{*}{ Groups } & \multicolumn{2}{|c|}{ TEOAE } & \multicolumn{2}{|c|}{ Inhibitory effect } \\
\hline & Present n (\%) & Absent n (\%) & Present n (\%) & Absent n (\%) \\
\hline GI $(n=13)$ & $7(53.8 \%)$ & $6(46.2 \%)$ & $0(0 \%)$ & $7(100 \%)$ \\
\hline GII $(n=14)$ & $7(50 \%)$ & $7(50 \%)$ & $2(28.6 \%)$ & $5(71.4 \%)$ \\
\hline$C G(n=15)$ & $15(100 \%)$ & $0(0 \%)$ & $10(66.6 \%)$ & $5(33.4 \%)$ \\
\hline$p$-value & \multicolumn{2}{|c|}{$0.003 *$} & \multicolumn{2}{|c|}{$0.005^{*}$} \\
\hline
\end{tabular}

Chi-square test. *p-value $<0.05$; GI: Group I; GII: Group II; CG: Control Group. 
Table 4 - Mean and standard deviation (in ms) of waves I, III, and V; interpeak intervals I-III, III-V, and I-V; and P300 wave latencies of both the ears, by group.

\begin{tabular}{|c|c|c|c|c|c|c|c|}
\hline \multirow[b]{2}{*}{ Groups } & Wave I & Wave III & Wave V & Interpeak I-III & Interpeak I-V & Interpeak III-V & P300 \\
\hline & Mean (SD) & Mean (SD) & Mean (SD) & Mean (SD) & Mean (SD) & Mean (SD) & Mean (SD) \\
\hline GI $(n=26)$ & $1.62(0.12)$ & $3.79(0.22)$ & $5.78(0.21)$ & $2.15(0.16)$ & $4.16(0.17)$ & $1.99(0.11)$ & 337.4 (32.98) \\
\hline GII $(n=28)$ & $1.60(0.14)$ & $3.78(0.19)$ & $5.81(0.25)$ & $2.18(0.17)$ & $4.21(0.22)$ & $2.02(0.20)$ & $323.21(38)$ \\
\hline CG $(n=30)$ & $1.57(0.09)$ & $3.74(0.13)$ & $5.69(0.15)$ & $2.16(0.11)$ & $3.96(0.58)$ & $2.1(0.59)$ & 317.8 (33.6) \\
\hline$p$-value & 0.374 & 0.596 & 0.108 & 0.819 & $0.040^{*}$ & 0.532 & 0.108 \\
\hline \multirow[t]{3}{*}{ Tukey's test } & - & - & - & - & $\mathrm{Gl}=\mathrm{Gll}$ & - & - \\
\hline & & & & & $\mathrm{Gl}=\mathrm{CG}$ & & \\
\hline & & & & & $\mathrm{GII} \neq \mathrm{CG}$ & & \\
\hline
\end{tabular}

ANOVA test. * $p$-value $<0.05$; SD: Standard deviation; GI: Group I; GII: Group II; CG: Control Group.

Table 5 - Distribution of electrophysiological assessment (BAEP, P300) results (normal or altered), by individual (number and percentage).

\begin{tabular}{|c|c|c|c|c|}
\hline & \multicolumn{2}{|c|}{ BAEP } & \multicolumn{2}{|c|}{ P300 } \\
\hline & Normal n (\%) & Altered n (\%) & Normal n (\%) & Altered n (\%) \\
\hline GI $(n=13)$ & $8(61.5 \%)$ & $5(38.5 \%)$ & $10(77 \%)$ & $3(23 \%)$ \\
\hline GII $(n=14)$ & $6(42.8 \%)$ & $8(57.2 \%)$ & $14(100 \%)$ & $0(0 \%)$ \\
\hline$C G(n=15)$ & $14(93.3 \%)$ & $1(0.7 \%)$ & $14(93.3 \%)$ & $1(0.7 \%)$ \\
\hline$p$-value & \multicolumn{2}{|c|}{$0.014^{*}$} & \multicolumn{2}{|c|}{0.111} \\
\hline
\end{tabular}

Chi-square test. * ${ }^{*}$-value $<0.05$; GI: Group I; GII: Group II; CG: Control Group.

The frequent manifestation of auditory abnormalities, from the middle ear to the central auditory nervous system, in individuals with HIV/AIDS has already been known for some time (27). Nevertheless, some recent studies suggest that people with oxidative stress can refer to auditory complaints and present some alterations throughout the auditory system, even in the absence of abnormalities in pure-tone threshold audiometry $(28,29)$.

Thus, this study sought to verify the occurrence of auditory alterations in normal-hearing HIV-positive individuals (with and without exposure to anti-retroviral treatment) comparing them with normal-hearing individuals without the virus.

The findings in this study highlighted that the study groups GI and GII presented hearing thresholds significantly higher in relation to the $C G$, although still within normality standards in pure-tone threshold audiometry. Similarly, highfrequency audiometry showed higher hearing thresholds than the other two groups. These results suggest that there are mechanisms of HIV and of the ototoxic medications (especially in GII) (30-34) that are harmful to the cochlea, which can be related to oxidative stress; this was observed in a study of noise-exposed individuals with an increase in high-frequency thresholds, precociously indicating the existence of damage to the cochlea, even in the presence of hearing thresholds within normality in conventional audiometry (35).

Recent studies in noise-exposed animals suggest that, in addition to the vulnerability of cochlear hair cells because of oxidative stress, there may concomitantly be a process that would damage the synapsis between the hair cells and auditory nerve fibers. This alteration in the synapses could cause an alteration in the processing of acoustic information, even in the presence of hearing thresholds within normality, contributing to the presence of abnormalities, such as speechin-noise difficulties and/or tinnitus (11-13,36).

In the case of seropositive individuals participating in this study, the hearing thresholds of the conventional audiometry were within normality, while the absence of TEOAE was verified in approximately $50 \%$ of the individuals in GI and GII, which points to the existence of subclinical cochlear damage. Previous studies conducted in normal-hearing noise-exposed adults showed the absence of otoacoustic emissions for both types of evoked otoacoustic emissions $(37,38)$. Thus, the absence or decrease in the amplitude of the otoacoustic emissions can provide the first indications of cochlear damage (39-41).

Regarding the efferent auditory pathway's inhibitory effect, it was believed that the role of the olivocochlear efferent system was to protect the hair cells from noise exposure. However, after the vulnerability of the synapses between the hair cells and auditory nerve was discovered, some studies highlighted the efferent system's protective role against synaptopathy. Two studies on guinea pigs exposed to noise (42) and age effect (43), respectively verified that the section of the efferent bundle exacerbated synaptopathy (44).

Concerning our findings, only half of the individuals belonging to GI and GII could be assessed for the inhibitory effect since this can only be measured in individuals who had TEOAE present. Of these, more than $70 \%$ of the individuals in GII and $100 \%$ of those in GI had no inhibitory effect. As the number of individuals with absent responses differed by only two between the two groups among seven individuals, it was challenging to make assumptions about the possible differences between GI and GII. However, the percentage of the presence of the inhibitory effect in CG differed significantly in relation to GI and GII.

Accordingly, analyzing the absence of the efferent auditory pathway's inhibitory effect in more than $70 \%$ of the individuals in GI and GII, it can be suggested that these individuals present auditory alterations not restricted only to the cochlea. This is in agreement with the study by Carvallo et al. (45), which emphasized that the decrease or absence of the 
efferent system's inhibitory effect can be a risk marker for auditory alterations.

For the results concerning BAEP, this study agrees with previous findings suggesting that HIV-seropositive individuals have a higher percentage of alterations, indicating an impairment of the central auditory pathway, regardless of exposure to the anti-retroviral treatment $(46,47)$. However, regarding the localization of the alteration, Matas et al. (46) verified that the alteration of the lower brainstem was the most common; however, in this study, the groups with HIV showed statistically significant differences in the interpeak interval $\mathrm{I}-\mathrm{V}$, denoting diffused alteration in the brainstem, even for hearing within normality.

A previous study detected high levels of oxidative stress markers in the central nervous system of HIV-infected humans (48), which could explain the presence of more BAEP alterations in the HIV groups when compared with the CG, and even more alterations in the individuals exposed to anti-retroviral medications.

Concerning the P300 latency values in this study, these were similarities between groups, suggesting that individuals with HIV positive, with and without exposure to antiretroviral treatment, did not present cognitive difficulties, behaving similar to the CG. This fact can be explained by the phase of AIDS the patients were in, as none of them were in the advanced stage of the disease when cognitive decline could occur. A previous study conducted by Fein et al. (49) emphasized that the P300 wave delay can be associated with the progression of the disease when cognitive impairment occurs. Another study demonstrated that in $20 \%$ of HIVinfected individuals, the first apparent symptom is neurological (50), with manifestations that can include auditory processing (51). Thus, future studies are needed to monitor the evolution of P300 responses in patients with HIV at different stages of the disease as well as to include tests that specifically assess cognitive function.

Oxidative stress has been shown to be an important factor in the pathogenesis of many diseases, including neurodegenerative diseases and AIDS. The increase in oxidative damage linked to mitochondrial DNA dysfunction contributes to aging, affecting different cell signaling systems and neuronal connectivity, potentially leading to the death of hair cells and neurons, as both are vulnerable to oxidative stress $(11,2,27)$.

A literature review conducted by Jong et al. (27) highlighted that HIV could affect the auditory system entirely, similar to what occurs in aging. The authors emphasized that synaptopathy could be present in individuals with HIV, even before cochlear damage. Therefore, it is fundamental to perform auditory function assessments of all individuals diagnosed with HIV, including other procedures besides conventional audiometry, such as the otoacoustic emissions assessment, the electrophysiological assessment, and the speech-in-noise test.

Hence, the findings in this study suggest that the alterations observed throughout the auditory pathway (and not identified through conventional audiometry) can be related to oxidative stress caused by HIV itself and the antiretroviral medications (in the case of GII). Therefore, the need for new studies to be developed on the subject is emphasized, as well as the use of complementary examinations, in assessing individuals with HIV, for the early detection of possible auditory alterations.

\section{CONCLUSION}

Normal-hearing HIV-positive individuals, with and without exposure to anti-retroviral treatment, presented with poor performance in the behavioral, electroacoustic, and electrophysiologic audiological procedures, when compared with the CG, indicating the presence of auditory alterations even with hearing thresholds within normality. These findings suggest that oxidative stress can be an influencing factor in these alterations.

This study was carried out at the Speech Therapy and Audiology Research Laboratory in the Auditory Evoked Potentials of the Speech Therapy Course, in the Department of Physiotherapy, Speech Therapy and Audiology, and Occupational Therapy, Medical School, University of São Paulo.

\section{ACKNOWLEDGMENTS}

This study was approved by the Ethics Committee for Analysis of Research Projects (CAPPesq) of the Clinical Directorate of Hospital de Clínicas and Medical School of the University of São Paulo, under the protocol number 1026/04.

\section{AUTHOR CONTRIBUTIONS}

Matas CG and Samelli AG designed, provided interpretative analysis, analyzed data, wrote, and critically revised the paper. Padilha FY and Angrisani RM provided interpretative analysis, wrote, and critically revised the paper.

\section{REFERENCES}

1. Barré-Sinoussi F, Chermann JC, Rey F, Nugeyre MT, Chamaret S, Gruest J, et al. Isolation of a T-lymphotropic retrovirus from a patient at risk for acquired immune deficiency syndrome (AIDS). Science. 1983;220 (4599):868-71. https://doi.org/10.1126/science.6189183

2. Ministério da Saúde do Brasil. Revisão da definição nacional de casos de Aids em indivíduos com 13 anos de idade ou mais, para fins de vigilância epidemiológica. J Bras Doenças Sex Transm. 1999;11:31-7. http://bvsms. saude.gov.br/bvs/publicacoes/074_02revisao.pdf

3. Montaner JS, Hogg RS, O'Shaughnessy MV. Emerging international consensus for use of antiretroviral therapy. Lancet. 1997;349(9058):1042. https://doi.org/10.1016/S0140-6736(05)62289-1

4. Khoza-Shangase K. Highly active antiretroviral therapy: Does it Sound toxic? J Pharm Bioallied Sci. 2011;(1):142-53. https://doi.org/10.4103/ 0975-7406.76494

5. Cohen BE, Durstenfeld A, Roehm PC. Viral Causes of Hearing Loss: A Review for Hearing Health Professionals. Trends Hear. 2014;18:23312 16514541361. https://doi.org/10.1177/2331216514541361

6. Ivanov AV, Valuev-Elliston VT, Ivanova ON, Kochetkov SN, Starodubova ES, Bartosch B, et al. Oxidative Stress during HIV Infection: Mechanisms and Consequences. Oxid Med Cell Longev. 2016;2016:8910396. https:// doi.org/10.1155/2016/8910396

7. Berra CM, Menk CF, Mascio PD. Estresse oxidativo, lesões no genoma e processos de sinalização no controle do ciclo celular. Química Nova. 2006;29(6):1340-4.

8. de Oliveira MC, Schoffen JP. Oxidative stress action in cellular aging. Braz Arch Biol Technol. 2010;53(6):1333-42. https://doi.org/10.1590/S151689132010000600009

9. Shin DH, Martinez SS, Parsons M, Jayaweera DT, Campa A, Baum MK Relationship of Oxidative Stress with HIV Disease Progression in HIV HCV Co-infected and HIV Mono-infected Adults in Miami. Int J Biosci Biochem Bioinforma. 2012;2(3):217-223.

10. Aukrust P, Luna L, Ueland T, Johansen RF, Müller F, Frøland SS, et al. Impaired base excision repair and accumulation of oxidative base lesions in CD4 + T cells of HIV-infected patients. Blood. 2005;105(12):4730-5. https://doi.org/10.1182/blood-2004-11-4272

11. Marí M, Morales A, Colell A, García-Ruiz C, Fernández-Checa JC. Mitochondrial glutathione, a key survival antioxidant. Antioxid Redox Signal. 2009;11(11):2685-700. https://doi.org/10.1089/ars.2009.2695

12. Hong H, Dooley KE, Starbird LE, Francis HW, Farley JE. Adverse outcome pathway for aminoglycoside ototoxicity in drug-resistant tuberculosis treatment. Arch Toxicol. 2019;93(5):1385-1399. https://doi.org/ 10.1007/s00204-019-02407-8 
13. Shi L, Chang Y, Li X, Aiken S, Liu L, Wang J. Cochlear Synaptopathy and Noise-Induced Hidden Hearing Loss. Neural Plast. 2016;2016:6143164. https: / /doi.org/10.1155/2016/6143164

14. Song Q, Shen P, Li X, Shi L, Liu L, Wang J, et al. Coding deficits in hidden hearing loss induced by noise: the nature and impacts. Sci Rep. 2016;6:25200. https://doi.org/10.1038/srep25200

15. Dewey RS, Hall DA, Guest H, Prendergast G, Plack CJ, Francis ST. The Physiological Bases of Hidden Noise-Induced Hearing Loss: Protocol for a Functional Neuroimaging Study. JMIR Res Protoc. 2018;7(3):e79. https://doi.org/10.2196/resprot.9095

16. Kunst LR, Garcia MV, Machado AK, Barbisan F, Silveira AF. Emissões otoacústicas e biomarcadores do estresse oxidativo em escolares de região fumicultura. CoDAS. 2014;26(3):219-25. https://doi.org/10.1590/23171782/201420140489

17. Henderson D, Bielefeld EC, Harris KC, Hu BH. The role of oxidative stress in noise-induced hearing loss. Ear Hear. 2006;27:1-19. https://doi.org/ 10.1097/01.aud.0000191942.36672.f3

18. Hickox AE, Larsen E, Heinz MG, Shinobu L, Whitton JP. Translational issues in cochlear synaptopathy. Hear Res. 2017;349:164-71. https://doi. org/10.1016/j.heares.2016.12.010

19. Schaette R, McAlpine D. Tinnitus with a normal audiogram: physiological evidence for hidden hearing loss and computational model. J Neurosci. 2011;31(38):13452-7. https://doi.org/10.1523/JNEUROSCI.2156-11.2011

20. Plack CJ, Barker D, Prendergast G. Perceptual consequences of "hidden" hearing loss. Trends Hear. 2014;18:2331216514550621. https://doi.org/ $10.1177 / 2331216514550621$

21. Lobarinas E, Salvi R, Ding D. Selective Inner Hair Cell Dysfunction in Chinchillas Impairs Hearing-in-Noise in the Absence of Outer Hair Cell Loss. J Assoc Res Otolaryngol. 2016;17(2):89-101. https://doi.org/ 10.1007/s10162-015-0550-8

22. World Health Organization. WHO, 2014. Available from: http://www. who.int/pbd/deafness/hearing_impairment_grades/en/

23. Dhar S, Hall JW. Otoacoustic Emissions. Principles, procedures and protocols. Plural Publishing. 2012.

24. Ryan S, Kemp DT. The influence of evoking stimulus level on the neural suppression of transient evoked otoacoustic emissions. Hear Res. 1996; 94(1-2):140-7. https://doi.org/10.1016/0378-5955(96)00021-4

25. McPherson, DL. Late potentials of the auditory system. Singular Publishing Group. 1996.

26. Colado Simão AN, Victorino VJ, Morimoto HK, Reiche EM, Panis C. Redox na infecção pelo vírus da imunodeficiência humana tipo 1 (HIV-1) e suas implicações clínicas. Curr HIV Res. 2014;13(2):143-50. https://doi. org/10.2174/1570162X13666150313152422

27. de Jong MA, Luder A, Gross M. Main Aspects of Peripheral and Central Hearing System Involvement in Unexplained HIV-Related Hearing Complaints. Front Neurol. 2019;10:845. https://doi.org/10.3389/fneur. 2019.00845

28. Luque AE, Orlando MS, Leong UC, Allen PD, Guido JJ, Yang H, et al. Hearing function in patients living with HIV/AIDS. Ear Hear. 2014;35(6): e282-90. https://doi.org/10.1097/AUD.0000000000000064

29. Parthasarathy A, Kujawa SG. Synaptopathy in the Aging Cochlea: Characterizing Early-Neural Deficits in Auditory Temporal Envelope Processing. J Neurosci. 2018;38(32):7108-19. https://doi.org/10.1523/ JNEUROSCI.3240-17.2018

30. Pappas DG Jr, Chandra f1p4ar HK, Lim J, Hillman DE. Ultrastructural findings in the cochlea of AIDS cases. Am J Otol. 1994;15(4):456-65.

31. Lin C, Lin SW, Weng SF, Lin YS. Increased risk of sudden sensorineural hearing loss in patients with human immunodeficiency virus aged 18 to 35 years: a population-based cohort study. JAMA Otolaryngol Head Neck Surg. 2013;139(3):251-5. https://doi.org/10.1001/jamaoto. 2013.1709

32. van der Westhuizen Y, Swanepoel de W, Heinze B, Hofmeyr LM. Auditory and otological manifestations in adults with HIV/AIDS. Int J Audiol. 2013;52(1):37-43. https://doi.org/10.3109/14992027.2012.721935

33. Maro II, Moshi N, Clavier OH, MacKenzie TA, Kline-Schoder RJ, Wilbur $\mathrm{JC}$, et al. Auditory impairments in HIV-infected individuals in Tanzania. Ear Hear. 2014;35(3):306-17. https://doi.org/10.1097/01.aud.00004391 01.07257.ed
34. Fokouo JV, Vokwely JE, Noubiap JJ, Nouthe BE, Zafack J, Minka Ngom ES, et al. Effect of HIV Infection and Highly Active Antiretroviral Therapy on Hearing Function: A Prospective Case-Control Study From Cameroon. JAMA Otolaryngol Head Neck Surg. 2015;141(5):436-41. https://doi.org/ 10.1001/jamaoto.2015.125

35. Liberman MC, Epstein MJ, Cleveland SS, Wang H, Maison SF. Toward a Differential Diagnosis of Hidden Hearing Loss in Humans. PLoS One. 2016;11(9):e0162726. https://doi.org/10.1371/journal.pone.0162726

36. Liberman MC, Kujawa SG. Cochlear synaptopathy in acquired sensorineural hearing loss: Manifestations and mechanisms. Hear Res. 2017;349:138-147. https://doi.org/10.1016/j.heares.2017.01.003

37. Vinck BM, Van Cauwenberge PB, Leroy L, Corthals P. Sensitivity of transient evoked and distortion product otoacoustic emissions to the direct effects of noise on the human cochlea. Audiology. 1999;38(1):44-52. https://doi.org/10.3109/00206099909073001

38. Slliwinska-Kowalska M, Kotylo P, Hendler B. Comparing changes in transient-evoked otoacoustic emission and pure-tone audiometry following short exposure to industrial noise. Noise Health. 1999; 1(2):50-57.

39. Lalaki G. Noise Induced Hearing Loss (NIHL) and OAEs. 6th EFAS meeting. 2003. https://www.otoemissions.org/index.php/en/oae-news/ 149-july-september-2003-oaes-in-early-detection-and-monitoring-of-noiseinduced-hearing-loss-nihl

40. Torre P 3rd, Hoffman HJ, Springer G, Cox C, Young M, Margolick JB, Plankey M. Cochlear function among HIV-seropositive and HIV-seronegative men and women. Ear Hear. 2014;35(1):56-62. https://doi.org/ 10.1097/AUD.0b013e3182a021c8

41. Khoza-Shangase K. An analysis of auditory manifestations in a group of adults with AIDS prior to antiretroviral therapy. Afr J Infect Dis. 2011;5: 11-22. https://doi.org/10.4314/ajid.v5i1.66506

42. Maison SF, Usubuchi H, Liberman MC. Efferent feedback minimizes cochlear neuropathy from moderate noise exposure. J Neurosci. 2013;33: 5542-52. https:/ / doi.org/10.1523/JNEUROSCI.5027-12.2013

43. Yin Y, Liberman LD, Maison SF, Liberman MC. Olivocochlear innervation maintains the normal modiolar-pillar and habenular-cuticular gradients in cochlear synaptic morphology. J Assoc Res Otolaryngol. 2014;15(4): 571-83. https:/ /doi.org/10.1007/s10162-014-0462-z

44. Kujawa SG, Liberman MC. Synaptopathy in the noise-exposed and aging cochlea: Primary neural degeneration in acquired sensorineural hearing loss. Hear Res. 2015;330(Pt B):191-9. https://doi.org/10.1016/j.heares. 2015.02.009

45. Carvallo RM, Sanches SG, Ibidi SM, Soares JC, Durante AS. Inibição eferente das emissões otoacústicas em neonatos prematuros. Braz J Otorhinolaryngol. 2015;81(5):491-7. https://doi.org/10.1016/j.bjorl.2015.07. 008

46. Matas CG, Samelli AG, Angrisani RG, Magliaro FC, Segurado AC. Brainstem Auditory Evoked Potential in HIV-Positive Adults. Med Sci Monit. 2015;21:3172-8. https://doi.org/10.12659/MSM.894958

47. Matas CG, Samelli AG, Magliaro FCL, Segurado A. Audiological and electrophysiological alterations in HIV-infected individuals subjected or not to antiretroviral therapy. Braz J Otorhinolaryngol. 2018;84(5):574-582. https://doi.org/10.1016/j.bjorl.2017.07.003

48. Zhang Y, Wang M, Li H, Zhang H, Shi Y, Wei F, et al. Accumulation of nuclear and mitochondrial DNA damage in the frontal cortex cells of patients with HIV-associated neurocognitive disorders. Brain Res. 2012;1458:1-11. https://doi.org/10.1016/j.brainres.2012.04.001

49. Fein G, Biggins CA, MacKay S. Delayed latency of the event-related brain potential P3A component in HIV disease. Progressive effects with increasing cognitive impairment. Arch Neurol. 1995;52(11):1109-18. https://doi.org/10.1001/archneur.1995.00540350103022

50. Levy RM, Bredesen DE, Rosenblum ML. Neurological manifestations of the acquired immunodeficiency syndrome (AIDS): experience at UCSF and review of the literature. J Neurosurg. 1985;62(4):475-95. https://doi. org /10.3171/jns.1985.62.4.0475

51. Zhan Y, Fellows AM, Qi T, Clavier OH, Soli SD, Shi X, et al. Speech in Noise Perception as a Marker of Cognitive Impairment in HIV Infection. Ear Hear. 2018;39(3):548-54. https://doi.org/10.1097/AUD.000000000 0000508 